\title{
An Empirical Study Affecting Content Characteristics of Cyber Culture on Acceptance Intention
}

\author{
Ha-Kyun Kim1)
}

\begin{abstract}
Cyber culture is recognized as a significant change in social life. Its influence is continuously increasing in the cultural space created through computer - based communication and the Internet. Cyber culture is a new world created through the interconnection of social networks. Data, information, and knowledge that can be obtained through the Internet are stored in large quantities. This knowledge is newly produced or shared through new techniques. Cyber culture is another society formed in cyberspace. It can be interpreted as a new value, philosophy, norm, belief, consciousness that unifies peoples in cyber space. Based on the test on content characteristics of cyber culture, behavior attitude, and acceptance intention, the findings of the research are the following. First, reply has significant effect on the behavior attitude; second, discussion has significantly effect on the behavior attitude; third, relationship has no significant effect on the behavior attitude; fourth, information has significant effect on the behavior attitude; fifth, social participation has no significant effect on the behavior attitude; sixth, behavior attitude has significant effect on the acceptance intention.
\end{abstract}

Keywords : Discussion, Information, Relationship, Reply, Social, Participation, Cyber, Culture

\section{Introduction}

Cultural diversity means a degree of difference in the culture that appears in various societies. The development of information technology has created a new cultural space called cyberspace, which can contribute to the enhancement of cultural diversity[1]. Cyber space is a virtual space rather than a physical dimension. In cyber space, there are many opportunities for participation and expression without being limited by time or space. It is open to all users, therefore it is easy to express minority or individual opinions. In addition, the boundaries of the group are easily extended, so that it is easy to share a variety of interests, opinions, and information.

Cyber culture is perceived as a significant change in social life. Its influence is continuously increasing in computer - based communication and cultural space created through Internet.

Received(April 23, 2019), Review Result(1st: May 16, 2019, 2nd: July 8, 2019), Accepted(September 10, 2019)

1) (Professor) 48513 Division of Business, Pukyoung National Univ. 45, Yongso-ro, Nam-Gu. Busan, Korea email: kimhk@pknu.ac.kr 
Cyber culture is a new world created through the interconnection of social networks. It is a space where data, information, and knowledge that can be obtained through the Internet are stored enormously. This knowledge is newly produced or shared through new techniques.

This study divided the content characteristics of cyber culture into reply, discussion, relationship, information and social participation. This study is an empirical analysis on the content characteristics of cyber culture to the behavioral attitude and acceptance intention. In order to explain the content characteristics of cyber culture, the relationship of factors was tested by adopting PLS (Partial Least Squares) method.

\section{Theoretical Background}

\subsection{Content Characteristics of Cyber Culture}

Cyber culture is a place to utilize cyber space. Therefore, various types of cyber culture can be divided. Among the types of cyber culture, content characteristics can be divided into replay, discussion, relationship, information, and social participation.

Replies are the act of writing or reading about the opinion of others in the virtual space. Recently, the interest in the writing and reading activities of the Internet discussion space is rising. In other words, I am interested in peoples are participating in virtual space through writing and reading.

Discussions are based on open discussion for various purposes in cyberspace. Depending on the topic of the forum, it can have a positive impact on the social norm or community, and it can have a bad influence. The establishment of sound discussion culture in cyberspace is necessary to create a healthy society. In order to secure the reliability of cyberspace, it is necessary to construct a sound information network.

Relationship, it is possible to form relationships with other people through cyberspace. Discussions, copyrights, or comments are the main reason for using cyberspace, but another intention is to maintain or expand relationships among people. It is controversial whether the person who spend a lot of time in cyberspace is more interested in cyberspace than being with family or friends[2].

Information is retrieved, stored, transmitted, and communicated through cyberspace. In general, the Internet is called the sea of information. In cyberspace, knowledge is a collection of data, information, and communication on the Internet.

Social participation is a social-oriented act through cyberspace. Social participation in 
cyberspace is popularized. Cyber space users raise issues through a common information network and act accordingly. As the social themes become more common, online users are more subject-oriented and more likely to be mobilized according to information networks.

\subsection{Behavior Attitude and Acceptance Intention}

In planning behavior theory, attitude refers to specific behavior attitude[3]. It is a function relation between the results that can be shown by a specific behavior in a behavior attitude and the value it gives to the result. In other words, attitudes are self-assessments of their overall behavior and favorable or unfavorable responses to their behavior.

Acceptance is the degree of subjective likelihood of deciding whether to accept cyberculture based on beliefs and identities about cyberculture[4]. It refers to the emotional reaction to the use of new technologies or services. In the measurement of new systems, the acceptance of the system and the intention to use are recognized as the most important concepts[5]. The success of the system is based on its acceptability despite of entries and acceptance of new systems. The continuing acceptance of new information technology is a success measure of the new system. The Theory of Reasoned Action (TRA) has been applied in various studies in relation to acceptance. TRA is the theory that attitudes and beliefs analyze the relationship between individual's will and actual behavior[6]. According to the TRA, consumers can predict behavior in hypotheses that they can perceive and control their behavior.

\section{Research Design}

\subsection{Research Model}

This study focuses on analyzing the influence of cyber culture's content characteristics on behavior attitude and acceptance intention in Social Networking Service(SNS). The research model based on previous research is shown in [Figure 1].

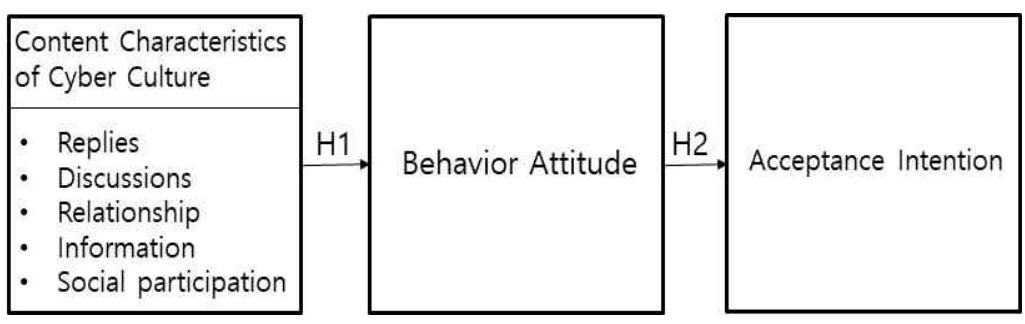

[Fig. 1] Research Model 


\subsection{Research Hypothesis}

3.2.1 The Hypotheses on the Content Characteristics of Cyber Culture and Behavioral Attitude

The content characteristics of cyber culture were classified into five categories: reply, discussion, relationship, information, and social participation. Therefore, hypotheses of the study are as follow.

Hypothesis H1-1; Reply will have a significant effect on behavior attitude.

Hypothesis H1-2; Discussion will have a significant effect on the behavior attitude.

Hypothesis H1-3; Relationship will have a significant effect on the behavior attitude.

Hypothesis H1-4; Information will have a significant effect on behavior attitude.

Hypothesis H1-5; Social participation will have a significant effect on behavior attitude.

\subsubsection{Hypothesis about Attitude of Behavior and Acceptance Intention}

Behavioral attitudes can be crucial factors affecting acceptance. Therefore, in this study, based on the previous research, hypothesis was set assuming that attitude toward behavior intends to increase acceptance intention.

Hypothesis H2; Behavior attitude will have a significant effect on acceptance intention.

\subsection{Empirical Analysis and Results}

\subsubsection{Data Collection and Sample Characteristics}

A total of 320 users responded to the survey. The basic statistics survey is as follows. $62 \%$ of respondents are men, and $48 \%$ are women. Relatively male is higher than female. Next, the average age was 33.7 years. Most of the respondents are young. $43 \%$ of the students were employed the occupation, followed by self-employed $(31 \%)$, office workers $(20 \%)$ and others $(6 \%)$.

\subsubsection{Method of Analysis of Data}

For the questionnaire analysis, SPSS 22.0 and Smart PLS 2.0, a structural equation package, 
were used for the basic statistics. Concentration validity tests the factor load value, construction reliability (CR) and average variance extraction (AVE) of each factor. Generally, the factor load value is more than 0.6 , the construction reliability value is more than 0.7 and average variance extraction is more than 0.5 . The discriminant validity is not affected because the root mean square values of the average variance extraction are greater than the correlation coefficient.

[Table 1] Reliability and Internal Consistency

\begin{tabular}{|c|c|c|c|c|}
\hline Variable & Factor loading & AVE & C. $\mathrm{R}$. & Cronbach's a \\
\hline \multirow{4}{*}{ Reply } & 0.755 & \multirow{4}{*}{0.627} & \multirow{4}{*}{0.901} & \multirow{4}{*}{0.852} \\
\hline & 0.718 & & & \\
\hline & 0.868 & & & \\
\hline & 0.860 & & & \\
\hline \multirow{4}{*}{ Discussion } & 0.686 & \multirow{4}{*}{0.623} & \multirow{4}{*}{0.868} & \multirow{4}{*}{0.797} \\
\hline & 0.753 & & & \\
\hline & 0.835 & & & \\
\hline & 0.870 & & & \\
\hline \multirow{3}{*}{ Relationship } & 0.841 & \multirow{3}{*}{0.734} & \multirow{3}{*}{0.892} & \multirow{3}{*}{0.818} \\
\hline & 0.894 & & & \\
\hline & 0.833 & & & \\
\hline \multirow{3}{*}{ Information } & 0.982 & \multirow{3}{*}{0.669} & \multirow{3}{*}{0.568} & \multirow{3}{*}{0.901} \\
\hline & 0.902 & & & \\
\hline & 0.877 & & & \\
\hline \multirow{2}{*}{ Social participation } & 0.936 & \multirow{2}{*}{0.905} & \multirow{2}{*}{0.941} & \multirow{2}{*}{0.807} \\
\hline & 0.965 & & & \\
\hline \multirow{4}{*}{ Behavior attitude } & 0.903 & \multirow{4}{*}{0.745} & \multirow{4}{*}{0.960} & \multirow{4}{*}{0.914} \\
\hline & 0.883 & & & \\
\hline & 0.801 & & & \\
\hline & 0.857 & & & \\
\hline \multirow{3}{*}{ Acceptance intention } & 0.908 & \multirow{3}{*}{0.850} & \multirow{3}{*}{0.949} & \multirow{3}{*}{0.923} \\
\hline & 0.942 & & & \\
\hline & 0.916 & & & \\
\hline
\end{tabular}

[Table 2] Correlation and Discriminant Validity

\begin{tabular}{|c|c|c|c|c|c|c|c|c|}
\hline Variable & AVE & 1 & 2 & 3 & 4 & 5 & 6 & 7 \\
\hline Reply & 0.629 & 0.793 & & & & & & \\
\hline Discussion & 0.623 & 0.521 & 0.789 & & & & & \\
\hline Relationship & 0.734 & 0.640 & 0.434 & 0.856 & & & & \\
\hline Information & 0.669 & 0.270 & 0.137 & 0.313 & 0.817 & & & \\
\hline Social participation & 0.903 & 0.438 & 0.428 & 0.603 & 0.003 & 0.950 & & \\
\hline Behavior attitude & 0.745 & 0.629 & 0.613 & 0.310 & 0.352 & 0.139 & 0.863 & \\
\hline Acceptance intention & 0.850 & 0.631 & 0.632 & 0.573 & 0.325 & 0.322 & 0.512 & 0.921 \\
\hline
\end{tabular}




\subsubsection{Verification of Structural Model}

The structural model uses Smart PLS 2.0 and the structural coefficient is used to derive the path coefficient and the coefficient of determination $\left(\mathrm{R}^{2}\right)$ between the variables of the research model. The coefficient of determination $\left(R^{2}\right)$ for behavior attitude (0.409) and acceptance intention (0.512) was high.

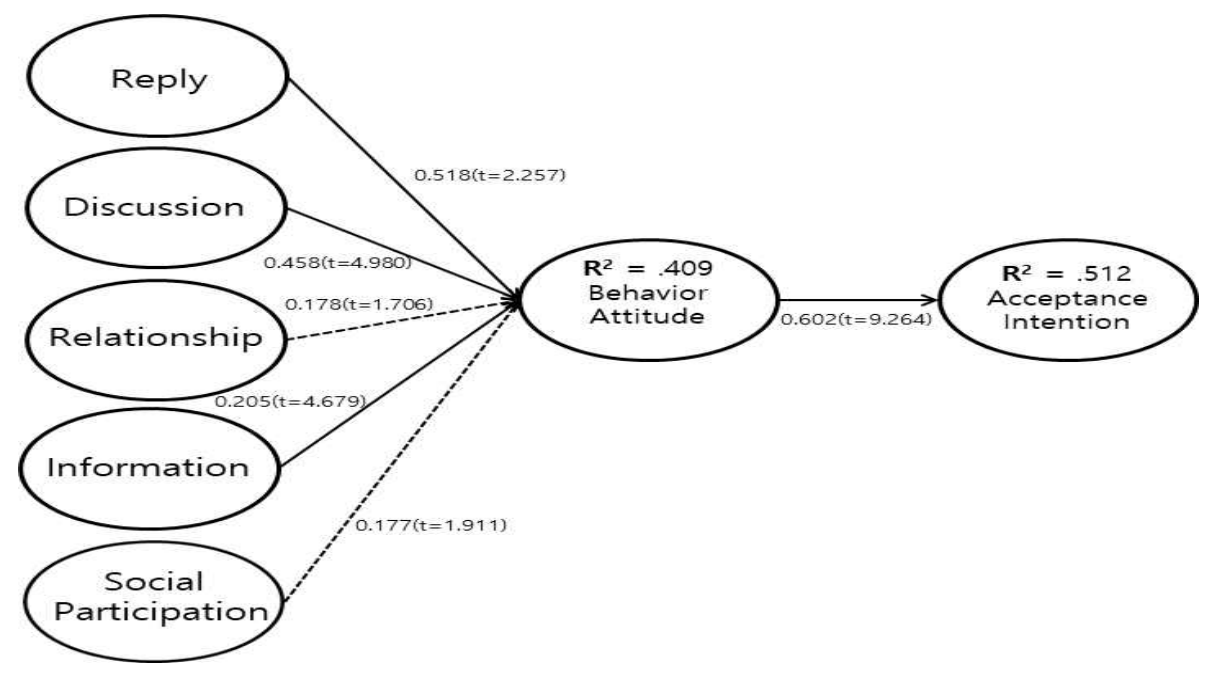

[Fig. 2] The Results of Research Model

In hypothesis H1-1, comment and behavior attitude $(\beta=0.518, t=2.257, p<0.05)$ were found to have a significant effect. Comments in the cyber culture environment can cause cyber problems in the behavior attitude. In the contemporary society where the opponent of the dialogue is insufficient, the comment actually affects the cyber world. Discussion and behavioral attitudes $(\beta=0.458, t=4.90, p<0.05)$ were found to have a significant influence in hypothesis H1-2. The more the discussion in cyber culture, the lower the problem of attitude of behavior. The relationship between hypothesis $\mathrm{H} 1-3$ and behavioral attitude $(\beta=0.178, t=1.706, p>0.05)$ did not have a significant effect. This is different from previous studies[2]. In the research of state the name of the author, the relationship in cyberspace differs from the general relationship between society and family, and it is not necessary to expand the relationship in cyberspace. In cyber culture, the relationship is not related to the behavior attitude. Therefore, the relationship in cyberspace is not related to the behavior attitude. This is probably because the relationship between people in the cyberspace is not important. The information and behavioral attitude of Hypothesis H1-4 $(\beta=0.205, \mathrm{t}=4.679, \mathrm{p}<0.05)$ showed significant influence. The difference in 
information can change the behavior attitude. The social participation and behavioral attitude of hypothesis H1-5 ( $\beta=0.177, \mathrm{t}=1.911, \mathrm{p}>0.05)$ did not have a significant effect, which differs from previous studies[7]. This is explained by the fact that social participation in cyberspace and behavior attitude are not related. Social participation in cyberspace is not as important as general social participation. Behavioral attitude and acceptance intention of hypothesis $\mathrm{H} 2$ ( $\beta$ $=0.602, \mathrm{t}=9.264, \mathrm{p}<0.05)$ were found to have a significant effect. Behavioral attitudes influence acceptance intentions.

\section{Conclusion}

This investigated the relationship between cyber cultural contents characteristics on behavior attitude and acceptance intention through empirical studies. The positive factors for cyber culture are self-refining and refining themselves in cyberspace[8]. The most effective way to reduce problems in cyberspace is self-restraint. It is necessary to spread the atmosphere of asking to be aware of the fact that the person is demeaning and causing problems with the other person. The biggest negative factor on cyber space was the verbal violence caused by anonymity in various ways[9]. Therefore, self-control in cyberspace is important. Language violence should be eradicated in cyber culture and increase intimacy of each other. The self-control in cyberspace and the respect with other users can strengthen the communication capacity.

The results of the study showed that cyber culture's content characteristics on behavior attitude and acceptance intention can be explained as follows: First, the comment had a significant effect on the attitude of the act. Second, the discussion had a significant effect on the behavior attitude. Third, the relationship did not have a significant effect on the behavior attitude. Fourth, information had a significant effect on the behavior attitude. Fifth, social participation did not affect the behavior attitude significantly. Sixth, behavior attitude influenced acceptance intention significantly.

Based on this study, an empirical model of cyber cultural contents, behavior attitude, and acceptance intention was proposed. So far, empirical research has been meaningful in the absence of existing research on cyber cultural contents, behavior attitude, and acceptance intention. In addition, users who want to develop cyber culture can create a practical level plan to improve cyber culture by recognizing the behavior attitude and the acceptance intention. 


\section{References}

[1] D. Jo, Inequality Discourses on Cyberspace and Cultural Citizenship, The Journal of Social Science, (2017), Vol.24, No.1, pp.57-74, DOI: 10.46415 /jss.2017.03.24.1.57

[2] H. Lee, A Study on Characteristics and Development Plan of Internet Culture in Korea, Korea Information Society Development Institute, (2008)

[3] J. Oh, A Study on the Impulsive Buying of Digital Contents Using Theory of Planned Behavior :Focused on Sensation Seeking Tendency, Proceeding paper of the Korean Academic Association of Business Administation Autumn Conference, (2007), November, pp.477-504.

[4] J. L. Dyck, N. R. Gee and J. A.-A. Smither, The changing construct of computer anxiety for younger and older adults, Computers in Human Behavior, (1998), Vol.14, No.1, pp.61-77, DOI: https://doi.org/10.1016/S0747-5632(97)00032-0

[5] F. D. Davis, A technology acceptance model for empirically testing new end-user information system: Theory and results, Massachusetts Institute of Technology, Doctoral Dissertation in Sloan School of Management, (1986)

[6] R. Ayagari, V. Grover, and R. Purvis, Techno stress: Technological Antecedents and Implications, MIS Quarterly, (2011), Vol.35, No.4, pp.831-858, DOI: https://doi.org/10.2307/41409963

[7] D. Jo, Characteristics of Deviant Behaviors and Social Control on Cyberspace, Information Society \& Media, (2006), Vol.10, No.1, pp.73-971.

[8] S. Park, Information Ethics Education for the Formation of Sound Cyber Culture, Journal of Ethic and Culture, (2009), Vol.5, No.5, pp.273-322.

[9] K. Lee, Factors Influencing Cyber_Culture Reception and Policy Alternatives in the Internet Era, Social Science Research Review, (2009), Vol.25, No.4, pp.131-154, UCI: G704-001638.2009.25.4.003 